\title{
PENGARUH DISIPLIN DAN FASILITAS TERHADAP PRODUKTIVITAS KERJA KARYAWAN PADA PT TIGA SERANGKAI INTERNATIONAL CABANG LAMPUNG
}

\author{
Hepiana Patmarina \\ Yulandari \\ Program Studi Manajemen, Fakultas Ekonomi Dan Bisnis \\ Universitas Bandar Lampung, Indonesia
}

\begin{abstract}
Abstrak
Disiplin dan fasilitas merupakan faktor penting sebagai alat pengukur keberhasilan dalam menjalankan usaha. Karena semakin tinggi produktivitas kerja karyawan dalam perusahaan, berarti laba perusahaan dan produktivitas meningkat. PT Tiga Serangkai International Cabang Lampung sangat di butuhkan nya disiplin dan fasilitas agar hasil akhir yang dicapai karyawan sesuai dengan tujuan perusahaan.

Penelitian ini bertujuan untuk mengetahui seberapa besar pengaruh disiplin dan fasilitas terhadap produktivitas kerja karyawan PT Tiga Serangkai International Cabang Lampung. Metode pengumpulan data kuisoner menggunakan sampling jenuh, jadi semua populasi digunakan sebagai sampel, dengan jumlah responden adalah 38 orang. Pada penelitian ini variabel bebasnya terdiri dari disiplin dan fasilitas sedangkan variabel terikatnya adalah produktivitas kerja karyawan. Pengujian instrument menggunakan uji validitas dan realibilitas. Sedangkan metode analisis data dilakukan dengan analisis regresi linier berganda dengan uji $\mathrm{t}$ dan uji $\mathrm{F}$.

Hasil penelitian variabel independent $\left(X_{1}\right)$ diperoleh $t_{\text {hitung }}(1.177)>t_{\text {tabel }}(2,437)$ dan variabel $X_{2}$ $t_{\text {hitung }}(2.931)>\mathrm{T}_{\text {tabel }}(2,437)$. Maka variabel $\mathrm{X}_{1}$ berpengaruh secara parsial terhadap variabel $\mathrm{Y}$ dan variabel $\mathrm{X}_{2}$ berpengaruh secara parsial terhadap variabel $\mathrm{Y}$. Hasil uji $\mathrm{F}$ menunjukkan bahwa $\mathrm{F}_{\text {hitung }}$ $(16.415)>F_{\text {tabel }}(7,42)$, sedangkan signifikansi adalah $0,000<$ alpha pada taraf signifikansi 0,01 , maka Ho ditolak dan $\mathrm{Ha}$ di terima yang berarti variabel independent secara bersama-sama atau simultan mempengaruhi variabel dependen secara signifikan. Sedangkan koefisien determinasi $\left(\mathrm{R}^{2}\right)$ adalah sebesar 0.912 yang berarti bahwa variabel Disiplin dan Fasilitas mampu mmenjelaskan variabel Produktivitas kerja sebesar 0,912 atau 91,2\% sedangkan sisanya dipengaruhi oleh faktor lain yang tidak diteliti.
\end{abstract}

Kata Kunci : Disiplin, Fasilitas, dan Produktivitas Kerja.

Abstract

Discipline and facilities are important factors as a means of measuring success in running a business. Because the higher the work productivity of employees in the company, means the company's profit and productivity increases. PT Tiga Serangkai International Lampung Branch really needed its discipline and facilities, so that the final results achieved by employees were in accordance with the company's goals.

This study aims to determine how much influence the discipline and facilities on the work productivity of employees of PT Tiga Serangkai International Lampung Branch. The questionnaire data collection method uses saturated sampling, so all populations are used as samples, with the number of respondents being 38 people. In this study the independent variables consist of discipline and facilities, while the dependent variable is employee work productivity. Testing instruments using validity and reliability tests. While the method of data analysis is done by multiple linear regression analysis with $t$ test and $F$ test.

The results of the study of independent variables (X1) obtained tcount $(1.177)>T$ table $(2,437)$ and X2 thitung variables $(2,931)>T$ table $(2,437)$. Then the X1 variable has a partial effect on the $Y$ variable and X2 variable has a partial effect on the $Y$ variable. The $F$ test results show that $F$ counts (16,415)> Ftable (7.42), while the significance is 0,000<alpha at the 0.01 significance level, then Ho is rejected and $\mathrm{Ha}$ is accepted which means that the independent variables simultaneously or simultaneously affect the dependent variable significantly. While the coefficient of determination (R2) is 
equal to 0.912 which means that the Discipline variable and Facilities are able to explain the work productivity variable of 0.912 or $91.2 \%$ while the rest is influenced by other factors not examined.

Keywords: Discipline, Facilities and Work Productivity.

\section{Pendahuluan}

Perusahaan merupakan suatu usaha besar yang dikelola ataupun dijalankan perorangan atau secara bersama-sama (beberapa orang) yang mempunyai modal besar dengan maksud untuk mencapai tujuan mengelola perusahaannya sendiri tetapi harus dibantu oleh karyawannya. Oleh karena itu, antara perusahaan dengan karyawan harus dapat bekerja sama untuk mencapai tujuan yang diinginkan.

Dalam mewujudkan tujuan yang ingin dicapai pada kenyataannya sering mengalami hambatan, kenyataan ini disebabkan oleh tidak mudahnya mengintegrasikan kepentingan setiap para anggota di dalam suatu perusahaan untuk mencapai suatu tujuan yang diinginkan..

Secara umum produktivitas diartikan sebagai hubungan antara hasil nyata maupun fisik dengan masukan yang sebenarnya. Disiplin dan fasilitas erat pula kaitannya dengan produktivitas kerja karyawan. jika karyawan tidak diberikan fasilitas dan disiplin yang baik maka akan mempengaruhi produktivitas kerja karyawan, produktivitas digunakan sebagai alat sarana untuk menganalisa dan mendorong keefektifan kerja, karena produktivitas merupakan perbandingan hasil yang dicapai dengan keseluruhan sumber daya.

Target produktivitas kerja karyawan PT Tiga Serangkai International Cabang Lampung merupakan suatu pencapaian perusahaan yang harus dilakukan oleh setiap karyawan. produktivitas kerja karyawan tersebut menjadi hal yang harus dicapai oleh setiap karyawan pada setiap bulannya. Karyawan yang memiliki tingkat disiplin dan fasilitas yang tinggi terhadap pekerjaannya, secara tidak langsung akan mempengaruhi tingkat produktivitasnya, sebaliknya jika disiplin dan fasilitas rendah menyebabkan produktivitas menurun.

Sehingga berdasarkan uraian di atas, maka penulis mengambil judul dalam penyusunan tugas akhir ini adalah "Pengaruh Disiplin dan Fasilitas Terhadap Produktivitas Kerja Karyawan Pada PT. Tiga Serangkai International Cabang Lampung.

\section{Landasan Teori}

\section{DISIPLIN (X1)}

Menurut R. Supomo dan Eti Nurhayati (2018) bahwa disiplin merupakan suatu sikap atau perilaku seorang karyawan atau pegawai dalam suatu organisasi atau instansi untuk selalu taat, menghargau, dan menghormati segala peraturan dan norma yang telah ditentukan oleh institusi, agar tujuan organisasi atau instansi tersebut dapat tercapai.

Indikator Disiplin menurut Fandi Afandi (2018) meliputi: 1). Masuk kerja tepat waktu. 2). Penggunaan waktu secara efektif. 3). Tidak pernah mangkir atau tidak kerja. 4). Mematuhi semua peraturan organisasi atau perusahaan. 5). Target pekerjaan. 6). Membuat laporan kerja harian.

Karyawan yang mempunyai disiplin yang tinggi akan merasa berat meninggalkan pekerjaan jika belum selesai, bahkan akan merasa senang jika dapat menyelesaikan tepat waktu, dia mempunyai target dalam menyelesaikan suatu pekerjaan sehingga selalu memprioritaskan pekerjaan mana yang perlu diselesaikan terlebih dahulu.

\section{FASILITAS (X2)}

Untuk mencapai tujuan perusahaan yang ada banyak faktor yang mendukung, salah satu diantaranya adalah fasilitas kerja karyawan merupakan faktor pendukung bagi kelancaran tugas yang mereka kerjakan, sehingga pekerjaanya dapat dikerjakan sesuai dengan yang diharapkan. Fasilitas menurut Ovidiu secara sederhana yang dimaksud dengan fasilitas adalah sarana fisik yang dapat memperoses suatu masukan (input) menuju keluaran (output) yang diinginkan.

Indikator fasilitas harus sesuai dengan apa yang dibutuhkan karyawan dengan tujuan untuk meningkatkan produktivitas kerjanya. Indikator Fasilitas Menurut Ermiati dan Sembiring (2014) adalah: 1). Sesuai dengan kebutuhan. 2). Mampu mengoptimalkan hasil kerja. 3). Mudah dalam penggunaan. 3). Mempercepat proses kerja. 4). Penempatan ditata dengan benar. 


\section{PRODUKTIVITAS KERJA (Y)}

Produktivitas memiliki peranan penting dalam pencapaian tujuan organisasi atau perusahaan. Produktivitas didefinisikan sebagai rasio dari hasil kerja dengan waktu yang dibutuhkan untuk menghasilkan produk dari seseorang tenaga kerja (Edy Sutrisno).

Indikator produktivitas kerja Menurut Pandi Afandi (2018) mengemukakan bahwa ada beberapa faktor yang yang digunakan dalam pengukuran produktivitas kerja meliputi :

1). Kuantitas kerja adalah merupakan suatu hasil yang dicapai oleh karyawan dalam jumlah tertentu dengan perbandingan standar ada atau ditetapkan oleh perusahaan. 2). Kualitas kerja adalah merupakan suatu standar hasil yang berkaitan dengan mutu dari suatu produk yang dihasilkan oleh karyawan dalam hal ini merupakan suatu kemampuan karyawan dalam menyelesaikan pekerjaan secara teknis dengan perbandingan standar yang ditetapkan oleh perusahaan. 3). Ketepatan waktu merupakan tingkat suatu aktivitas diselesaikan pada awal waktu yang ditentukan, dilihat dari sudut koordinasi dengan hasil output serta memaksimalkan waktu yang tersedia untuk aktivitas lain.

\section{Metode Penelitian}

Metode penelitian adalah "Suatu proses berpikir dari penentuan masalah, melakukan pengumpulan data, baik buku-buku maupun melalui observasi, melakukan pengolahan berdasarkan data yang ada sampai dengan penarikan kesimpulan dari masalah penelitian (Sugiyono, 2009). Dalam penelitian ini desain penelitian yang digunakan adalah penelitisn deskriptif menggunakan metode kuantitatif. Metode deskriptif yang digunakan penulis untuk menguji mengenai pengaruh disiplin dan fasilitas terhadap produktivitas kerja karyawan.

Dalam melakukan penyebaran kuisioner agar dapat mengukur perepsi karyawan pada PT. Tiga Serangkai International Cabang Lampung. Untuk memperoleh data yang diperlukan, teknik yang digunakan adalah pengisian kuisioner. Metode kuisioner atau angket adalah daftar pertanyaan yang diberikan pengguna, maka digunakan skala likert.

\section{Hasil dan Pembahasan}

\section{Uji Validitas}

Untuk melakukan pengujian validitas suatu instrumen kuesioner dapat digunakan metode statistik SPSS 17. Menurut hasil pengolahan data, ditunjukkan bahwa pada umumnya rata-rata instrumen kuesioner sangat valid. Hal ini ditunjukkan oleh nilai $r$ hitung $>r$ tabel dan nilai sig antara 0,000-0,001.

\section{Uji Reliabilitas}

Untuk menguji reliabilitas dilakukan dengan menggunakan Koefisien Reliabilitas (Cronbach Alpha). Suatu konstruk atau variabel dikatakan reliabel jika memberikan nilai Cronbach Alpha > 0,60 (Juliansyah Noor, 2014:131). Hasil uji reliabilitas instrumen kuesioner sebagaimana yang terdapat dalam lampiran skripsi ini dapat disimpulkan dalam Tabel 4.5 berikut ini :

Tabel 4.5

Ringkasan Hasil Uji Reliabilitas

\begin{tabular}{|l|l|l|}
\hline \multicolumn{1}{|c|}{ Variabel } & Alpha & Keterangan \\
\hline Disiplin (X1) & 0.824 & Reliable \\
\hline Fasilitas (X2) & 0.848 & Reliable \\
\hline $\begin{array}{l}\text { Produktifitas } \\
\text { Kerja (Y) }\end{array}$ & 0.852 & Reliable \\
\hline
\end{tabular}

Sumber : data diolah, 2018

Berdasarkan tabel di atas, diketahui bahwa nilai alpha instrumen penelitian pada masing-masing variabel lebih besar dari nilai yang diisyaratkan, yaitu sebesar 0.60. Dengan demikian, keseluruhan instrumen kuesioner dalam penelitian ini adalah reliable (dapat dipercaya) karena telah memenuhi syarat minimal yang telah ditentukan.

\section{Analisis Deskriptif}

Analisis deskriptif merupakan analisis yang akan membahas semua variabel dalam penelitian ini. Didalam penelitian ini menggunakan analisis pencapaian skor kategorinya jawaban responden per variabel, dengan tujuan untuk mengetahui gambaran deskriptif mengenai jawaban responden dalam penelitian ini. Terutama mengenai variabelvariabel penelitian yang digunakan.

\section{Alat Asumsi}

\section{Uji Asumsi Klasik}

\section{Uji Normalitas}

Uji normalitas digunakan untuk mengetahui apakah populasi data berdistribusi normal atau tidak. Regresi yang baik adalah regresi yang memiliki data yang berdistribusi normal.Uji normalitas dalam penelitian ini menggunakan uji statistik Descriptive Statistics 
Shapiro-Wilk merupakan uji normalitas menggunakan fungsi distribusi kumulatif. Data dinyatakan bedistribusi normal jika signifikasi lebih besar dari 5\% atau 0,05. Dasar pengambilan keputusan adalah berdasarkan probabilitas, yaitu :

Jika nilai probabilitas $>0,05$ maka Ho diterima Jika nilai probabilitas $\leq 0,05$ maka Ho ditolak Jika signifikasi pada nilai Shapiro-Wilk $\leq 0,05$, maka Ho ditolak, jadi data residual berdistribusi tidak normal.

Jika signifikasi pada nilai Shapiro-Wilk $>0,05$, maka Ho diterima, jadi data residual berdistribusi normal. Hasil uji normalitas (Uji Shapiro-Wilk) menunjukan nilai Sig 0,064, 0,052, dan 0,083 hal ini menunjukan bahwa nilai signifikasi lebih besar dari nilai tingkat kepercayaan $\alpha=0,05$, oleh karena itu dapat disimpulkan bahwa Ho diterima yang berarti residual terdistribusi dengan normal.

\section{Uji Multikolinearitas}

Uji multikolinearitas bertujuan untuk menguji apakah model regresi ditemukan adanya korelasi antar variabel bebas. Model regresi yang baik seharusnya bebas tidak terjadi korelasi diantara variabel independen. Jika terjadi korelasi, maka dinamakan terdapat masalah multikolinearitas. Nilai yang umum dipakai untuk menunjukkan adanya multikolinearitas adalah nilai tolerance $<0,1$ atau sama dengan nilai VIF $>$ 10. Dan sebaliknya apabila VIF $<10$ maka tidak terjadi multikolinearitas.

Berdasarkan hasil uji multikolinieritas (Uji VIF) yang telah dilakukan menunjukan bahwa nilai VIF kurang dari 10 dan nilai tolerance lebih dari 0,10 yang berarti bahwa model regresi dinyatakan tidak mengandung multikolinieritas.

\section{Analisis Regresi Linear}

Untuk menganalisis data yang diperoleh dari hasil penelitian di lapangan, digunakan analisis kualitatif dan kuantitatif. Analisis kuantitatif digunakan untuk membuktikan hipotesis yang diajukan dengan menggunakan model analisis Regresi Berganda.

Berdasarkan hasil diatas dimasukan ke dalam bentuk regresi linier berganda, sehingga persamaan sebagai berikut :

$$
\mathrm{Y}=6.309+1.382 \mathrm{X} 1+1.113 \mathrm{X} 2+\text { et }
$$

Keterangan :

$\mathrm{Y}=$ Produktivitas Kerja Karyawan

$\mathrm{X} 1=$ Disiplin

$\mathrm{X} 2=$ Fasilitas

\section{Koefisien Determinasi $\left(\mathbf{R}^{2}\right)$}

Koefisien determinan $\left(\mathrm{R}^{2}\right)$ dimaksudkan untuk mengetahui tingkat ketepatan paling baik dalam analisis regresi, dimana hal yang ditunjukkan oleh besarnya koefisiensi determinasi $\left(\mathrm{R}^{2}\right)$ antara 0 (nol) dan 1 (satu). Koefisien determinasi $\left(\mathrm{R}^{2}\right)$ nol variable independent sama sekali tidak berpengaruh terhadap variable dependen. Apabila koefisien determinasi semakin mendekati satu, maka dapat dikatakan bahwa variable independent berpengaruh terhadap varibel dependen. Selain itu koefisien determinasi dipergunakan untuk mengetahui presentase perubahan variable terikat $(\mathrm{Y})$ yang disebabkan oleh variabel bebas (X).

Berdasarkan hasil pengujian diketahui koefisien determinasi $\left(\mathrm{R}^{2}\right)$ adalah sebesar 0.912 yang berarti bahwa variabel Disiplin dan Fasillitas mampu menjelaskan variabel Produktivitas Kerja sebesar 0,912 atau 91,2\% sedangkan sisanya dipengaruhi oleh faktor lain yang tidak diteliti.

\section{Pengujian Hipotesis}

\section{Uji F}

Dalam penelitian ini untuk

mengetahui tingkat signifikansi pengaruh variable-variabel independent secara bersamasama (simultan) terhadap variable dependen dilakukan dengan menggunakan uji $\mathrm{F}$ test yaitu dengan cara membandingkan antara $\mathrm{F}$ hitung dan F tabel pada taraf nyata $\alpha=0,01$.

Hasil pengujian dengan bantuan program SPSS, diperoleh F-hitung sebesar 86.239 dengan tingkat probabilitas 0.000 (signifikan). Sedangkan F-tabel sebesar 7,42. Dengan demikian maka Fhitung lebih besar dari F-tabel $(16.415>7,42)$ dan juga probabilitas jauh lebih kecil dari 0.01. dengan demikian $\mathrm{H}_{0}$ ditolak dan $\mathrm{H}_{\mathrm{a}}$ diterima, yang berarti secara bersama-sama bahwa disiplin $\left(\mathrm{X}_{1}\right)$ dan fasilitas $\left(\mathrm{X}_{2}\right)$ berpengaruh terhadap produktifitas kerja karyawan $(\mathrm{Y})$.

\section{Uji t}

Pengujian hipotesis dengan Uji $t$ dimaksudkan untuk menguji kemaknaan atau keberartian koefisien regresi partial. Pengujian melalui uji t dilakukan dengan membandingkan thitung dengan t-tabel pada taraf nyata $\alpha=0.01$.

Berdasarkan hasil analisis uji t untuk variabel disiplin menunjukkan hasil penelitian tidak dapat menolak hipotesis nol (Ho) yang menyatakan Disiplin Kerja tidak berpengaruh Positif dan Signifikan terhadap Produktivitas Kerja". Dengan 
demikian, Ha diterima dengan nilai beta dalam unstandardized coefficients variabel Disiplin menunjukkan angka sebesar 1.382 yang artinya adalah hipotesis pertama dapat dikonfirmasi atau terdukung.

Untuk variabel fasilitas terhadap produktivitas kerja karyawan hasil penelitian tidak dapat menolak hipotesis nol (Ho) yang menyatakan "Fasillitas tidak berpengaruh Positif dan Signifikan terhadap Produktivitas Kerja". Dengan demikian, Ha diterima dengan nilai beta dalam unstandardized coefficients variabel Disiplin Kerja menunjukkan angka sebesar 1.113 yang artinya adalah hipotesis kedua dapat dikonfirmasi ${ }^{3}$ ) atau terdukung.

\section{Kesimpulan}

Berdasarkan dari penelitian yang dilakukan, maka dapat ditarik kesimpulan sebagai berikut :

1) Variabel disiplin berpengaruh signifikan terhadap produktivitas kerja karyawan pada PT. Tiga Serangkai International Cabang Lampung, artinya semakin tinggi tingkat kedisiplinan karyawan pada PT. Tiga Serangkai International Cabang Lampung maka produktivitas akan meningkat.

2) Variabel fasilitas berpengaruh signifikan terhadap produktivitas kerja karyawan pada PT. Tiga Serangkai International Cabang Lampung. Semakin baik fasilitas yang telah disediakan perusahaan kepada karyawan, maka produktivitas kerja karyawan pun akan meningkat.

3) Disiplin dan fasilitas sangat berpengaruh terhadap produktivitas kerja karyawan pada PT. Tiga Serangkai International Cabang Lampung. Hal ini dapat diartikan, produktivitas kerja akan semakin meningkat apabila disiplin dan fasilitas pada PT. Tiga Serangkai International Cabang Lampung juga ditingkatkan.

\section{Saran}

Berdasarkan hasil penelitian, pembahasan, dan kesimpulan diatas, maka diajukan beberapa saran sebagai berikut :

1) Berdasarkan hasil studi penelitian yang ditunjukkan, terutama variabel fasilitas. Diharapkan perusahaan harus lebih memperhatikan fasilitas yaitu computer, printer, almari, meja dan kursi tamu, rak buku, kipas angin dan AC agar lebih diperbanyak jumlah sehingga dapat meningkatkan produktivitas kerja karyawan.

2) Pada penelitian selanjutnya diharapkan peneliti dapat mengembangkan peneliltian dengan mengevaluasi pernyataan kuesioner, responden dengan tempat yang berbeda, dan variabel yang berbeda. Hasil pengujian yang diperoleh diharapkan dapat digunakan sebagai acuan di bidang studi pengaruh disiplin kerja dan fasilitas kerja terhadap produktivitas kerja karyawan, sebab konsep-konsep yang dikonstruksi mendukung model yang dikemukakan oleh studi-studi terdahulu.

\section{Daftar Pustaka}

Afandi, Pandi. 2018. Manajemen Sumber Daya Manusia Teori, Konsep dan Indikator. Yogyakarta. Zanafa Publishing.

Afriyani, Fitri dan Lena Farida. 2016. Pengaruh Disiplin Kerja Terhadap Produktivitas Kerja Karyawan Bagian Produksi Pabrik Kelapa Sawit PT. Perkebunan Nusantara $V$ SEI Rokan Kec. Pagaran Tapah Darussalam Kab Hulu. Jurnal.

Arikunto, S. 2013. Prosedur Penelitian Suatu Pendekatan Praktik. Jakarta. Rineka Cipta.

Ermiati dan Sembiring. 2014. Pengaruh Fasilitas dan Pengembangan Sumber Daya

.Bandung. Fokus Media.

Gaol, Chr L Jimmy. 2014. Human Capital Manajemen Sumber Daya Manusia. Jakarta. Kompas Gramedia.

Ghozali. 2013. Manajemen Analisis Multivariate Dengan Program SPSS. Semarang. Badan Penerbit Universitas Diponegoro.

Hasibuan, Malayu S.P. 2016. Manajemen Sumber Daya Manusia. Jakarta. PT Bumi Aksara.

Kholiyatun. 2017. Pengaruh Motivasi Kerja Dan Disiplin Kerja Terhadap Kinerja Karyawan Pada PT. Japfa Comfeed Unit Ketapang Kalianda Lampung Selatan. Skripsi.

Muslimin, Ria Mentari. 2016. Analisis Pelatihan Motivasi Dan Disiplin Kerja. Jurnal.

Noor, Juliansyah. 2014. Analisis Data Penelitian Ekonomi \& Manajemen. Jakarta. PT Grasindo.

Ovidiu. 2013. Employee Motivation and Organizational Performance. Economic Research ISSN. 
Rista. 2014. Efek Dari Pemimpin, Motivasi, dan Disiplin Kerja. Indonesia Accounting. Tulang Agung Regency.

Sayoto, Budi dan Herry Winarto. 2018. Jurnal Pengaruh Disiplin Kerja Dan Fasilitas Kerja Terhadap Produktivitas Kerja Karyawan MNCTV Bagian Produksi.

Sembiring. 2013. Budaya dan Kinerja Organisasi. Bandung. Fokus Media.

Setianingrum, Ika. 2017. Pengaruh Disiplin kerja, Fasilitas Kerja dan Pelatihan Karyawan terhadap produktivitas kerja karyawan pada Bank Syariah Kc Kedal. Skripsi.

Sugiyono. 2013. Metodologi Penelitian Bisnis. Jakarta. Selemba Empat.

----------- 2014. Metode Penelitian Bisnis (Pendekatan kuantitatif, Kualitatif, dan $R \& D)$. Bandung. Alfabeta.

Supomo, R dan Eti Nurhayati. 2018. Manajemen Sumber Daya Manusia. Bandung. Yrama Widya.

Sutrisno, Edy. 2016. Manajemen Sumber Daya Manusia. Kencana. Yrama Widya. 